\title{
DiscoverArchive
}

Retrieved from DiscoverArchive,

Vanderbilt University's Institutional Repository

This work was originally published as Viscusi, W. K. (1991). Age variations in risk perceptions and smoking decisions. The Review of

Economics and Statistics, 73(4), 577-588. 


\title{
The Review of Economics and Statistics
}

\begin{tabular}{lll}
\hline Vol. LXXIII & NOVEMBER 1991 & Number 4 \\
\hline
\end{tabular}

\section{AGE VARIATIONS IN RISK PERCEPTIONS AND SMOKING DECISIONS}

\author{
W. Kip Viscusi*
}

\begin{abstract}
The results of a national survey of smoking risks and smoking behavior are analyzed. Smoking risk perceptions follow the expected patterns given age differences in risk information acquired and differences in information associated with smoking status. Risk perceptions are greater as one moves to younger age cohorts, where overall lung cancer risks are substantially overestimated. These risk perceptions in turn have a negative effect on smoking decisions, where younger individuals behave no differently in terms of the manner in which they incorporate risk perceptions into their smoking decisions.
\end{abstract}

\section{Introduction}

$\mathrm{F}$ ROM the standpoint of market failure with respect to individual decisions under uncertainty, smoking behavior raises two classes of issues. First, do individuals understand the potential risks posed by their smoking decisions? Second, if they do understand these risks, do they take them into account when deciding whether they will smoke?

These concerns are particularly acute in the case of younger individuals, since most smokers initiate their smoking behavior when they are relatively young. In view of the considerable attention that has been focused on the costs associated with cessation of smoking, which have been designated a problem of "addiction" by the Surgeon General,' it becomes particularly important to determine whether young cigarette smokers understand the risks and act upon these risk perceptions in a responsible manner.

Received for publication April 5, 1990. Revision accepted for publication December 28, 1990.

*Duke University.

The author obtained the data used as a part of his work supporting the smoking litigation efforts of Jones, Day, Reavis \& Pogue. Research support was provided by the endowment of the George G. Allen chair. Patricia Born and Sharon Tennyson provided excellent research assistance. Gregory $\mathbf{M}$. Duncan and an anonymous referee provided a variety of useful suggestions.

${ }^{1}$ See U.S. Dept. of Health and Human Services (1988).
Evidence from other risk contexts does not inspire confidence in these decision-making capabilities. Younger drivers lead all age groups in motor vehicle fatality rates, where a major component of these accidents is attributable to teenage drunken driving. ${ }^{2}$ If irresponsible risktaking behavior in this decision context is reflected in others as well, then we would expect to find evidence of inadequate risk perceptions and failure to respond to risks when examining the smoking decisions of younger individuals.

An offsetting influence is that the mix of the information received by younger age groups will incorporate more adverse information with respect to the consequences of smoking. Public dissemination of risk information has been widespread, particularly over the past two decades. Moreover, the increased social controversy with respect to smoking has created heightened social awareness. One would expect that individuals whose experiences have been dominated by this more recent climate would have higher risk perceptions than those with a longer term perspective.

This paper will utilize a large national survey of smoking risk perceptions and smoking behavior to investigate the role of individual age with respect to smoking. These data will enable us to analyze smoking behavior as a case study in the economics of potentially risky consumption decisions. In particular, we will examine the level of subjective risk perceptions using probability assessments that make it possible to compare subjective perceptions with actual risk levels to determine the extent and direction of any bias. In

\footnotetext{
${ }^{2}$ The highest motor vehicle fatality rate is for the age group 15-24. See the National Safety Council (1988), p. 6. The role of teenage drinking and driving is explored in detail by Cook and Tauchen (1984). Blomquist (1988) overviews the role of alcohol consumption in models of auto safety.
} 
addition, the results will illuminate the role of different sources of information by analyzing the variations in risk perception with age and smoking status. Finally, it will be possible to assess how these risk perceptions are transmitted into smoking decisions, which is the main risk-taking decision of consequence in this consumption area. Although other studies of choices under uncertainty either in the product market or the labor market have addressed one or more of these issues, no previous study has considered all of these facets of economic decision making within a particular choice context. ${ }^{3}$

Studies of trends in smoking behavior, including Hamilton (1972) and Schneider, Klein, and Murphy (1981), have documented the responsiveness of smoking to shifts in information over time. However, the contemporaneous nature of the adverse smoking publicity, shifts in mandatory cigarette warnings, and Surgeon General's reports have complicated efforts to isolate the specific factors at work. Moreover, none of these studies examined the intervening linkage with risk perceptions to be considered here.

Although the data considered in this paper are quite extensive, they do not exhaust the range of concerns. For example, the cross-sectional nature of the data base will restrict our focus to issues of static consumption choices. The role of changing information over time and the impact of new information on changes in smoking behavior will not be explicitly examined. Moreover, the analysis will focus on only one major class of risks of smoking, lung cancer.

While the objective of the study is to provide a better understanding of how consumers make decisions involving risk, results for the cigarette

\footnotetext{
${ }^{3}$ For example, in the case of job safety, analysts have linked compensating differentials for risk with subjective and objective measures of risk, as in the case of Viscusi (1979) and Viscusi and O'Connor (1984), but these studies do not explore the perception bias issues in the same detail as possible with the cigarette data. Studies of driving behavior and seat belt use, such as Arnould and Grabowski (1981), do not explore specific aspects of risk perceptions. Recent studies of hazard warnings, such as Viscusi and O'Connor (1984), Viscusi and Magat (1987), Smith et al. (1988), and Smith and Johnson (1988), do not explore the perceptional bias and behavioral response linkages to the same extent as they are examined in this paper. The study by Kunreuther et al. (1978) of disasters is also very extensive.
}

choice situation are in no way meant to be representative of how consumers make risky choices in general. Indeed, much of the literature on the rationality of choice under uncertainty has indicated that the soundness of decisions varies considerably by decision context. A distinguishing feature of the cigarette decision is that the risks have been highly publicized. Cigarettes must be accompanied by mandatory product warnings, as must cigarette advertising. The Surgeon General is required by law to issue an annual report on smoking and health, which generally receives substantial media coverage. One index of the continuing media attention to smoking is the number of articles on smoking published by Reader's Digest -23 from 1980-1989, 19 from 1970-1979, and 17 from 1960-1969 (counts by author). Ringold and Calfee (1989) document the substantial prominence of health concerns in cigarette advertising since the 1920s. This advertising calls consumers' attention to a negative product attribute, which is highly unusual. There is also the potential for observable feedback'effects of smoking on one's health status that are likely to affect decisions in a repeated consumption situation. Smoking decisions are of particular interest in indicating how consumers respond to a prominent product risk communication effort.

After discussing the sample in section II, section III will model the formation of risk perceptions, with a major prediction being that smoking risk perceptions should be higher for younger age groups and for non-smokers. Using detailed data on lung cancer risk perceptions, one obtains results that accord quite closely with the expected patterns of information acquisition. Overall, young respondents overestimate the level of lung cancer risks. After outlining the econometric model in section IV, section $V$ provides a regression analysis of the determinants of risk perception to analyze the independent effect of variables, such as individual age. Evidence indicating that risk perceptions are higher in the case of younger age groups still may be consistent with market failure if the young do not respond to their perceptions when making their smoking decisions. The regression results in section VI indicate that the linkage of smoking risks to smoking behavior for the age range $16-21$ is not significantly different from that of older age groups. Section VII concludes this paper. 
TABle 1.-SAMPle Characteristics

\begin{tabular}{lc}
\hline \hline Variable & Mean (Std. Dev.) \\
\hline AGE16-21 (Respondent Age 16-21 d.v.) & 0.113 \\
& $(0.316)$ \\
AGE22-45 (Respondent Age 22-45 d.v.) & 0.512 \\
& $(0.500)$ \\
AGE46 + (Respondent Age 46 or older d.v.) & 0.368 \\
& $(0.482)$ \\
MALE (d.v.) & 0.366 \\
& $(0.482)$ \\
HOUSEHOLD SIZE (number) & 2.193 \\
& $(0.983)$ \\
SMOKER (d.v.) & 0.250 \\
& $(0.433)$ \\
PAST SMOKER (d.v.) & 0.248 \\
& $(0.432)$ \\
RISK & 0.426 \\
& $(0.269)$ \\
North East Metro (d.v.) & 0.170 \\
& $(0.376)$ \\
North East Nonmetro (d.v.) & 0.042 \\
& $(0.201)$ \\
North Central Metro (d.v.) & 0.178 \\
& $(0.382)$ \\
North Central Nonmetro (d.v.) & 0.086 \\
South Metro & $(0.280)$ \\
South Nonmetro & 0.187 \\
West Metro & $(0.390)$ \\
West Nonmetro & 0.129 \\
Sample Size & $(0.335)$ \\
& 0.169 \\
& $(0.374)$ \\
& 0.039 \\
& $(0.195)$ \\
& 3,119 \\
\hline
\end{tabular}

\section{Sample Characteristics}

The data base used for this analysis is a national survey of smoking behavior by a New York research firm, Audits and Surveys. ${ }^{4}$ The sample was based on a 1985 national telephone survey that was undertaken on a randomized basis, drawing from all four U.S. Census regions. The sampling procedure stratified each Census region into metropolitan and non-metropolitan areas. Sample size differences across areas reflected population differences. The regional breakdown of the sample is given in table 1 . The only sample screen was that the respondent had to be at least 16 years old.

After making contact with the house, a random selection procedure determined which household

\footnotetext{
${ }^{4}$ This survey was commissioned by a consortium of defense law firms representing the cigarette industry. See Viscusi (1990) for a companion analysis of these data.
}

member would be the respondent. ${ }^{5}$ Adults in the age group 22-45 comprised $51 \%$ of the sample, and men comprised $37 \%$. The primary age group of interest here is the young age group in the age range 16-21. Half of the sample were nonsmokers, and the remainder were equally divided between smokers and former smokers.

The central variable in the empirical analysis is the risk perception variable (RISK). The survey asked respondents how many of each group of 100 smokers would get lung cancer. By ascertaining the risk level with respect to a base population, the survey incorporated a procedure that has been shown to be a meaningful way to elicit probabilistic information in survey contexts. ${ }^{6}$ Risks viewed with respect to a base population are much more readily understood than, for example, probabilistic information. Overall, there were 3,119 complete survey responses, where the sample is limited to individuals with valid observations for the RISK variable, which is the key variable of interest. There were 381 individuals with missing RISK responses, or $11 \%$ of the sample. The non-respondents were similar to those with valid RISK responses except that older individuals were less likely to answer the RISK question. The possibility of sample selection bias will be explicitly addressed in the results below.

Although lung cancer represents an important risk of smoking, the wording of the risk perception question is not ideal. First, the question ascertained the overall risk perception for lung cancer, not the fatality rate from lung cancer.

\footnotetext{
${ }^{5}$ The interview began with a detailed series of questions to first determine the number of household members age 16 or above and then to ascertain the sex and relative ages of these individuals. These questions established an ordering of household members that provided a uniform basis for undertaking a random selection of the respondents from among those at home.

${ }^{6}$ This procedure of treating risks within the context of a total number of outcomes out of a base population has, for example, been used with success in Viscusi (1988) and Viscusi, Magat, and Huber (1987). In Viscusi (1988), I estimate the lung cancer fatality risk through a hazard warning study involving a base population of 11 million Illinois residents within the context of a written survey. The assessed lung cancer death risk from smoking of 0.33 is of a magnitude similar to the 0.43 lung cancer incidence rate assessed here. Testing of different risk denominators within the context of a telephone survey indicates that the 100 smoker denominator is the most easily understood. When, for example, respondents were given other base populations such as the total state population or 1000 smokers, they almost invariably ignored the denominator and gave the percentage or fraction of smokers who would develop lung cancer.
} 
This distinction is not of substantial consequence because the mortality risk from lung cancer is quite high. ${ }^{7}$ In addition, in a subsequent survey by the author, assessment of the lung cancer fatality rate from cigarette smoking was found to be somewhat lower, but quite similar to the overall lung cancer risk assessment. ${ }^{8} \mathrm{~A}$ potentially more important omission is that adverse health effects other than lung cancer were not included in the survey. Even if these survey results provide only a partial perspective on the overall risks of cigarette smoking, the findings are nevertheless instructive because of the importance of the lung cancer component. A partial focus on a single risk component is the dominant one in the economics of risk-dollar tradeoffs literature as, for example, job risk studies typically focus on wage premiums for fatality risks and do not analyze risk premiums for disease. In addition, individual awareness of lung cancer risks is strongly correlated with awareness of other risks of smoking, such as throat cancer and heart disease (see the Gallup Poll 1981), so that lung cancer risk perceptions serve in part as a proxy for overall smoking risk perceptions. ${ }^{9}$ To the extent that the incomplete coverage of the lung cancer risk perception variable proves to be of consequence, the analysis will note any potential biases below.

\section{The Risk Perception Model}

Let us treat the formation of risk perceptions within a Bayesian learning framework. In particular, we will use a beta distribution to characterize the learning process since this distribution is

\footnotetext{
${ }^{7}$ In particular, for untreated cases of lung cancer, $95 \%$ of all lung cancer patients are dead within a year. The five-year survival rate even for treated cases of lung cancer is also low. See Overholt, Neptune, and Ashraf (1975). Individuals may, however, overestimate their chance of survival of lung cancer. The 1978 American Cancer Society Survey indicated that $71 \%$ of smokers believed that there is a "very good chance" or a "fairly good chance" that lung cancer could be cured "if lung cancer is detected early." The quantitative significance of such qualitative risk assessments is unclear, and the probability of assessed early detection is not indicated. The same survey indicated that cigarette smoking led the list of cancer causes in the view of smokers and nonsmokers. See "Public Attitudes Toward Cancer and Cancer Tests," CA-A Cancer Journal for Clinicians, Vol. 30 (1980), pp. 92-98.

${ }^{8}$ In Viscusi (1988) I show that the assessed cigarette smoking death risk is 0.33 .

${ }^{9}$ Analysis of the trends in Gallup Poll results over time also indicates that trends in lung cancer risk perceptions follow those for other smoking risks.
}

highly flexible and is ideally suited to analyzing binary lotteries such as this. Assuming a normal distribution yields an identical mathematical structure but imposes far more stringent symmetry requirements. This approach was introduced by Viscusi (1985) and Viscusi and O'Connor (1984) and has also been successfully utilized by Smith and Johnson (1988). The formulation below introduces a variant of this model, recognizing three different sources of smoking risk information.

Individuals have three sources of information. First, they have their prior risk assessments $p$, which have associated informational content $\Psi_{0}$ (i.e., the informational weight placed on the prior is equivalent to observing $\Psi_{0}$ draws from a Bernoulli urn). The second source of information consists of direct and indirect individual experience. The individual may have been a cigarette smoker and formed a risk assessment based on the observed health effects (e.g., increased coughing), or one may learn about adverse health effects on others. Let $q$ denote the risk assessment derived from experience, and $\gamma_{0}$ be the associated informational content. The third source of risk information consists of information about smoking that has been communicated to the individual, ranging from newspaper stories to hazard warnings on cigarette packages. Let $r$ be the risk implied by this information and $\xi_{0}$ be its informational content. The final bit of notation is that it is useful to denote the fraction of the total informational content associated with each information source rather than its level, and we will drop the 0 subscript in this instance (i.e., $\Psi=$ $\Psi_{0} /\left(\Psi_{0}+\gamma_{0}+\xi_{0}, \gamma=\gamma_{0} /\left(\Psi_{0}+\gamma_{0}+\xi_{0}\right)\right.$, and $\xi=\xi_{0} /\left(\Psi_{0}+\gamma_{0}+\xi_{0}\right)$.

The individual's lung cancer risk perception function takes the simple additive form,

$$
R I S K=\frac{\Psi_{0} p+\gamma_{0} q+\xi_{0} r}{\Psi_{0}+\gamma_{0}+\xi_{0}}=\Psi p+\gamma q+\xi r
$$

so that the risk implied by each source of information is weighted by the fraction of the informational content associated with it.

The formulation in equation (1) is particularly instructive in interpreting variations in risk perception with age and smoking status. The rows in table 2 give lung cancer risk perceptions for dif- 
Table 2.- Variations in Risk Perceptions With Age and SMoking Status

MEAN RISK (STD. ERROR OF MEAN) BY GROUP

\begin{tabular}{lcccc}
\hline \hline Age Group & $\begin{array}{c}\text { Current } \\
\text { Smoker }\end{array}$ & $\begin{array}{c}\text { Former } \\
\text { Smoker }\end{array}$ & $\begin{array}{c}\text { Non- } \\
\text { Smoker }\end{array}$ & $\begin{array}{c}\text { All } \\
\text { Respondents } \\
\text { in Age Group }\end{array}$ \\
\hline$A G E 16-21$ & .445 & .429 & .511 & .490 \\
& $(.043)$ & $(.037)$ & $(.017)$ & $(.015)$ \\
AGE22-45 & .382 & .390 & .454 & .417 \\
& $(.011)$ & $(.013)$ & $(.010)$ & $(.006)$ \\
AGE46 + &. .328 & .421 & .456 & .418 \\
& $(.017)$ & $(.015)$ & $(.011)$ & $(.008)$ \\
All Ages & .368 & .408 & .464 & .426 \\
& $(.009)$ & $(.010)$ & $(.007)$ & $(.005)$ \\
\hline
\end{tabular}

ferent smoking groups, conditional on the age group, and the columns give risk perceptions for different age groups conditional on smoking status.

Suppose that publicly provided risk information conveys a higher risk than the individual's prior risk beliefs $(r>p)$ and experiences $(r>q)$. Even if the intent of the information campaign is to provide accurate information, limitations on individual processing of the information may lead to overassessments of the risk. As the risk perception literature has demonstrated, there is often a tendency for people to overassess highly publicized events. ${ }^{10}$ Media coverage of smoking risks dwarfs the coverage given to most other risks. Moreover, this coverage usually indicates that smoking is risky; it does not provide probabilistic information in any meaningful sense. If the saliency of the risk information creates a similar bias in the case of smoking, we would expect there to be overestimation of the risk. Other factors, such as the remoteness of the risk and the large size of the risk, may work in the opposite direction so that there is no unambiguous prediction from the risk perception literature pertaining to the direction of bias.

If, however, the sources of risk information have the associated probabilities indicated above, we would expect that as you move from the younger to the older age cohorts that the risk perception should decline. For younger individuals the role of experience with cigarettes will be less so that governmental information will play a

\footnotetext{
${ }^{10}$ See Camerer and Kunreuther (1989); Combs and Slovic (1979); Fischhoff et al. (1981); Lichtenstein et al. (1978); Viscusi (1985, 1988), and Viscusi and Magat (1987).
}

greater role, ${ }^{3}$ leading to a higher risk assessment. The Bayesian learning model also predicts a dampening of the drop-off with age:

$$
\frac{\partial^{2} R I S K}{\partial \xi_{0}^{2}}<0 \text { if } p, q<r .
$$

This pattern is borne out for the data in table 2. In particular, for each of the three smoking categories the adult population group has lung cancer risk perceptions that are significantly lower than for the young age group. ${ }^{11}$ In addition, when one moves to the oldest population group $(A G E 46+)$, the risk perception drops even more for current smokers, but for all respondent groups there is no significant decline in risk perceptions between the middle and oldest age groups. ${ }^{12}$ This diminishing effect of risk information is also consistent with a rational learning model.

The general pattern as one moves across the rows (from current smokers to former smokers and then to nonsmokers in any age group) is that the risk perception rises, which one would expect since we are moving toward groups with a higher proportion of their information coming from governmental sources. ${ }^{13}$ The only case where a rise does not occur (i.e., young current smokers have a higher risk assessment than young former smokers) involves a difference that is not statistically significant. Moreover, it is unclear which of the two groups has actually had more experience smoking cigarettes. In addition, the differences between the two groups are not statistically significant. The interpretation of the smoking status results is not as clearcut as the age variations

\footnotetext{
${ }^{11}$ The difference in means for the Age 16-21 group minus Age 22-45 group and the associated $95 \%$ confidence intervals are the following: $.063 \pm .035$ (current smokers), $.039 \pm .033$ (former smokers), .057 \pm .024 (nonsmokers), and .073 \pm .016 (all respondents).

${ }_{12}$ The difference in means and the associated $95 \%$ confidence levels for the $A G E 46+$ group minus the $A G E 22-45$ group are: $-.054 \pm .026$ (current smokers) and $.001 \pm .014$ (all respondents).

${ }_{13}$ The patterns for all age groups combined are statistically significant. Most, but not all, of these differences for particular age groups are statistically significant. The differences in RISK means and the associated $95 \%$ confidence interval for former smokers minus current smokers are $-0.016 \pm 0.080$ $\begin{array}{llll}(A G E 16-21), & 0.008 \pm 0.023 \quad(A G E 22-45), & 0.093 \pm 0.031\end{array}$ $(A G E 45+)$, and $0.040 \pm 0.020$ (all ages); for non-smokers minus current smokers the differences and $95 \%$ confidence intervals are $0.082 \pm 0.041($ AGE16-21), $0.064 \pm 0.022$ ( $A G E 22-45), 0.035 \pm 0.025(A G E 45+)$, and $0.056 \pm 0.016$ (all ages).
} 
Table 3.-Distribution of Risk Perception for Cigarette Smoking, Ages 16-21

\begin{tabular}{|c|c|c|c|c|}
\hline $\begin{array}{l}\text { Distribution } \\
\text { of Risk } \\
\text { Perceptions } \\
(\text { RISK) }\end{array}$ & $\begin{array}{l}\text { All Age } \\
\text { Groups }\end{array}$ & $\begin{array}{c}\text { All } \\
\text { Respondents } \\
\text { Age 16-21 }\end{array}$ & $\begin{array}{c}\text { All } \\
\text { Smokers }\end{array}$ & $\begin{array}{l}\text { Smokers } \\
\text { Age 16-21 }\end{array}$ \\
\hline$R I S K<.05$ & .052 & .031 & .092 & .083 \\
\hline $.05 \leq R I S K<.10$ & .046 & .034 & .051 & .067 \\
\hline $.10 \leq R I S K<.20$ & .117 & .088 & .130 & .117 \\
\hline $.20 \leq R I S K<.30$ & .136 & .117 & .146 & .133 \\
\hline $.30 \leq R I S K<.40$ & .090 & .094 & .114 & .117 \\
\hline $.40 \leq R I S K<.50$ & .052 & .063 & .050 & .067 \\
\hline $.50 \leq R I S K<.60$ & .239 & .188 & .228 & .083 \\
\hline $.60 \leq R I S K<.70$ & .070 & .097 & .056 & .017 \\
\hline $.70 \leq R I S K<.80$ & .084 & .105 & .050 & .083 \\
\hline $.80 \leq R I S K<.90$ & .042 & .088 & .027 & .067 \\
\hline $.90 \leq R I S K<1.00$ & .041 & .057 & .028 & .067 \\
\hline$R I S K=1.00$ & .030 & .037 & .026 & .100 \\
\hline Mean RISK & .426 & .490 & .368 & .445 \\
\hline (Std. Error of Mean) & $(.005)$ & $(.015)$ & $(.009)$ & $(.043)$ \\
\hline
\end{tabular}

because smoking status is the result of a discretionary decision. Other explanations, such as cognitive dissonance and the self-selection of people with low risk assessments into smoking, are also possible. $^{14}$

Table 3 provides a more detailed perspective on the distribution of risk perception levels. As is indicated by a comparison of the risk perceptions for the entire sample in all age groups and for the younger individuals, the younger respondents tend to have higher risk perceptions than their more senior counterparts. In particular, younger individuals are more concentrated in the higher risk perception categories than older individuals. Moreover, for all smoking status groups, the $A G E 16-21$ group has a significantly higher level of lung cancer risk perceptions. ${ }^{15}$

An interesting policy question is the extent to which individuals overestimate the risk. Thus, from the standpoint of market failure we are not simply concerned with the level of risk perceptions, but whether these perceptions are above or below the actual risk level. It should be emphasized that these assessments pertain only to the lung cancer risk, not all risks of smoking. The

\footnotetext{
${ }^{14}$ Akerlof and Dickens (1982) provide a discussion of economic models of cognitive dissonance.

${ }^{15}$ For the sample of all individuals irrespective of smoking status, the difference in means and the associated $95 \%$ confidence interval is $0.064 \pm 0.014$, and for smokers it is $0.077 \pm$ 0.032 .
}

overall smoking risk perception is what is pertinent for such broader policy judgments. ${ }^{16}$

Although the scientific basis for determining the lung cancer risk is not precise because of the difficult problems in tracking causality for diseases, the best estimates using information provided by the Surgeon General indicate that the "true" lung cancer risk is in the range from 0.05 to $0.10 .{ }^{17}$. Since table 3 provides detailed breakdowns by deciles, readers wishing to explore the sensitivity of the results to other reference risk levels can do so.

The overall implication of table 3 is that individuals assess the lung cancer risks associated with smoking as being greater than the "true" risk level, and the extent of overestimation is particularly great for the youngest age cohort. Moreover, the asymmetry of risk perceptions

\footnotetext{
${ }^{16}$ A subsequent survey $-\mathrm{I}$ have undertaken indicates that the overall assessed death risk from smoking exceeds the assessed lung cancer risk and the actual mortality risk but by less than the ratio of the overall smoking mortality rate to the smoking lung cancer rate. These other risk results appear in Viscusi (1992).

${ }^{17}$ The calculation of the overall risk level consisted of several components. The first is the number of lung cancer deaths per year, which is 110,000 , of which $85 \%$ are believed to be due to cigarette smoking (U.S. Dept. of Health and Human Services (1982), p. vi). To calculate the lung cancer risk level, one must divide the total number of lung cancer death risks by the number of smokers, which is a figure obtained from the U.S. Dept. of Commerce (1985), p. 119. Finally, the risk range is obtained by assuming lifetime smoking periods ranging from 30 to 60 years, which lead to an associated risk range of 0.05 to 0.10 .
} 
around the "true" risk leads to overestimation that greatly exceeds risk underestimation. The net effect is that only a small segment of the sample underestimates the actual risk level. In the case of young cigarette smokers, under $10 \%$ of the sample believes that the risk is less than 0.05 , and only $15 \%$ of the sample believes that the risk is less than 0.10 so that the overwhelming majority have risk assessments in excess of the estimated risk level.

The risk perceptions of those below the "true risk" level are quite different from those above this amount. For respondents with a risk threshold of 0.05 , the average value of $R I S K$ and its associated $95 \%$ confidence interval is $0.015 \pm$ 0.001 , whereas for respondents with RISK values greater than or equal to 0.05 , the mean RISK and its associated 95\% confidence interval is $0.449 \pm 0.005$. Similarly, with a risk threshold of 0.10 , one obtains $0.034 \pm 0.001$ for risk underestimators and $0.468 \pm 0.005$ for those with $R I S K \geq$ 0.10 .

An intriguing aspect of table 3 is the reasonably large fraction of smokers- $10 \%$ of all young smokers-who believe the risk level is 1.0 , yet they continue to smoke. Although rational explanations involving the role of time lags and discounting are no doubt possible, another contributing factor is that the assessed cases of lung cancer per 100 smokers tends to be clustered at salient numbers. Respondents assessing a RISK of 1.0 may believe that lung cancer is highly likely but not necessarily a certain outcome.

\section{The Equations to Be Estimated}

The beta distribution formulation in equation (1) leads quite directly to an empirical specification for purposes of estimation. The dependent variable in the risk perception equation pertains to lung cancer risks and not all risks of smoking. This equation provides only a partial assessment of the determinants of all smoking risk perceptions. The partial coverage creates no bias in the estimates for the determinants of lung cancer risk perceptions since the lung cancer variable is the dependent variable in the analysis.

If we let $X_{j i}$ be a vector of variables characterizing each source $j$ of information for person $i$ (i.e., $j=1$ for prior beliefs, $j=2$ for direct information transfer, and $j=3$ for smoking-related experience), and let $\alpha_{j}$ be the associated vector of coefficients, then the lung cancer risk perception equation to be estimated for person $i$ can be written

$$
\operatorname{RISK}_{i}=\alpha_{0}+\alpha_{1} X_{1 i}+\alpha_{2} X_{2 i}+\alpha_{3} X_{3 i}+u_{i}
$$

where $u_{i}$ is a random error term. ${ }^{18}$ The variables included in $X_{3 i}$ include the respondent's past and current smoking status. Past smoking decisions are predetermined and consequently can be treated as exogenous. Current smoking status likewise may be predetermined because of the long-term nature of such consumption decisions, but on theoretical grounds current smoking status could be endogenous. Although one cannot reject the possibility that smoking status is not endogenous, I will also include results that allow for the possibility of simultaneity. In addition, the potential for selectivity bias with respect to the lung cancer risk responses will be taken into account by including the inverse of the Mill's ratio using a probit estimation procedure described by Heckman (1976). This hazard rate term pertaining to the probability of a non-response to the RISK question will be denoted by $L A M B D A$. One can consequently rewrite equation (2) as

$$
\begin{aligned}
\text { RISK }_{i}= & \alpha_{0}+\alpha_{1} X_{1 i}+\alpha_{2} \dot{X}_{2 i}+\alpha_{3}^{\prime} X_{3 i}^{\prime} \\
& +\alpha_{4} \text { SMOKER }_{i}+\alpha_{5} L A M B D A_{i}+u_{i} .
\end{aligned}
$$

The dichotomous smoking decision is governed by the equation

$$
\text { SMOKER }_{i}=\beta_{0}+\beta_{1} Y_{1 i}+\beta_{2} \text { RISK }_{i}+\epsilon_{i},
$$

where $Y_{1 i}$ is a vector of variables pertaining to tastes for cigarettes and cigarette prices. Because of the discrete nature of smoking status, equation (4) will be estimated using probit analysis.

For the simultaneous equation estimation of equations (3) and (4) conventional two-stage least squares analysis is not appropriate because of the discrete nature of the smoking variable. Instead, I will adopt the procedure suggested by Maddala (1983, pp. 244-245). First, form the reduced form

\footnotetext{
${ }^{18}$ The implications of estimating $\ln (1+R I S K)$ are almost identical, but this formulation lacks the theoretical basis of the linear specification. Other nonlinear specifications of the risk perception equation led to results very similar to those yielded by equation (2), so the analysis will focus on the simple linear model.
} 
Table 4.-Lung Cancer Risk Assessment Eouations

\begin{tabular}{|c|c|c|c|c|c|}
\hline \multirow{2}{*}{$\begin{array}{l}\text { Independent } \\
\text { Variables }\end{array}$} & \multicolumn{5}{|c|}{ Coefficients (std. errors) } \\
\hline & 1 & 2 & 3 & 4 & 5 \\
\hline \multirow[t]{2}{*}{ Intercept } & $.4362^{a}$ & $.4790^{\mathrm{a}}$ & $.5175^{a}$ & $.5250^{a}$ & $.5143^{a}$ \\
\hline & $(.0172)$ & $(.0242)$ & $(.0246)$ & $(.0554)$ & $(.0354)$ \\
\hline \multirow[t]{2}{*}{$A G E 16-21$} & $.0736^{\mathrm{a}}$ & $.0711^{\mathrm{a}}$ & $.0546^{\mathrm{a}}$ & $.0554^{a}$ & $.0497^{a}$ \\
\hline & $(.0170)$ & $(.0170)$ & $(.0170)$ & $(.0170)$ & $(.0217)$ \\
\hline \multirow{2}{*}{$A G E 22-45$} & .0028 & -.0004 & -.0004 & .0055 & .0011 \\
\hline & $(.0104)$ & $(.0105)$ & $(.0104)$ & $(.0104)$ & $(.0150)$ \\
\hline \multirow[t]{2}{*}{$M A L E$} & $-.0564^{a}$ & $-.0556^{a}$ & $-.0489^{a}$ & $-.0480^{a}$ & $-.0484^{a}$ \\
\hline & $(.0100)$ & $(.0100)$ & $(.0099)$ & $(.0099)$ & $(.0100)$ \\
\hline \multirow[t]{2}{*}{ HOUSEHOLD SIZE } & .0041 & .0039 & .0032 & .0040 & .0037 \\
\hline & $(.0050)$ & $(.0051)$ & $(.0050)$ & $(.0050)$ & $(.0051)$ \\
\hline \multirow{2}{*}{$\begin{array}{l}\text { PAST SMOKER OR } \\
\quad \text { SMOKER }\end{array}$} & - & - & $-.0681^{a}$ & - & - \\
\hline & - & - & $(.0097)$ & - & - \\
\hline \multirow{2}{*}{$\begin{array}{l}\text { SMOKER } \\
\quad \text { (I.V.) }\end{array}$} & - & - & - & $-.0830^{a}$ & $-.0827^{a}$ \\
\hline & - & - & - & $(.0164)$ & $(.0164)$ \\
\hline \multirow{2}{*}{$\begin{array}{l}\text { PAST SMOKER } \\
\quad \text { (I.V.) }\end{array}$} & - & - & - & $-.0450^{a}$ & $-.0447^{a}$ \\
\hline & - & - & - & $(.0107)$ & $(.0107)$ \\
\hline \multirow{2}{*}{$\begin{array}{l}\text { LAMBDA } \\
\text { (Selectivity } \\
\text { bias term) }\end{array}$} & - & - & - & - & .0078 \\
\hline & - & - & - & - & $(.0187)$ \\
\hline \multicolumn{6}{|l|}{ Ideas Heard: } \\
\hline SHORTENS LIFE & - & $\begin{array}{r}-.0079 \\
(.0135)\end{array}$ & $\begin{array}{c}-.0084 \\
(.0134)\end{array}$ & $\begin{array}{c}-.0123 \\
(.0134)\end{array}$ & $\begin{array}{r}-.0123 \\
(.0134)\end{array}$ \\
\hline \multirow{4}{*}{$\begin{array}{c}\text { DANGEROUS TO } \\
\text { HEALTH } \\
\text { BAD, NOT } \\
\text { DANGEROUS }\end{array}$} & - & $-.0237^{a}$ & $-.0262^{a}$ & $-.0272^{a}$ & $-.0272^{a}$ \\
\hline & & $(.0140)$ & $(.0138)$ & $(.0138)$ & $(.0138)$ \\
\hline & - & $-.0382^{a}$ & $-.0360^{a}$ & $-.0362^{a}$ & $-.0362^{a}$ \\
\hline & & $(.0135)$ & $(.0134)$ & $(.0133)$ & $(.0133)$ \\
\hline \multirow{2}{*}{$\begin{array}{l}\text { NOT BAD } \\
\quad \text { FOR HEALTH }\end{array}$} & - & .0089 & .0051 & .0023 & .0021 \\
\hline & & $(.0133)$ & $(.0132)$ & $(.0132)$ & $(.0132)$ \\
\hline $\bar{R}^{2}$ & .02 & .02 & .03 & .05 & .05 \\
\hline
\end{tabular}

analogs of the risk perception and smoking probability equations. ${ }^{19}$ The risk perception equation (3) is then estimated by OLS after the SMOKER variable is replaced by the probit estimate of the smoking probability from the reduced form SMOKER equation. The smoking probability equation (4) is estimated by probit after replacing $R I S K$ by the reduced form estimate of $R I S K_{i}$.

\section{The Lung Cancer Risk Perception Equation}

Table 4 reports several specifications of the lung cancer risk perception equation in which different sets of variables are included so as to distinguish the different influences at work. The

\footnotetext{
${ }^{19}$ In each case I augment the set of instruments by 50 detailed regional dummy variables. Moreover, for the RISK equation I also include a variable for whether $R I S K$ was above or below its median in a procedure developed by Wald (1940) and described in Kmenta (1986, pp. 361-362).
}

low explanatory power of all three equations in table 4 suggests that factors other than those reflected in these demographic and broad informational variables account for smoking risk perceptions. The focus here is not on developing a predictive model but on testing specific hypotheses relating to respondent age.

Equation 1 in table 4 includes only the background variables and regional dummy variables, which reflect differences in experience, the character of information that has been acquired, and regional price differences. The youngest age group (YOUNG) has higher risk perceptions, which is consistent with the earlier view that the smoking information the youngest cohort has received includes a much higher fraction of high risk messages. The Surgeon General's efforts and the character of cigarette warnings have become more stringent in recent years, and there has been a dramatic increase in social pressure against smoking. As predicted, the young will be more heavily 
affected by the recent anti-smoking campaigns. Males have a significantly lower risk perception, on average. This pattern may reflect sex differences in attitudes toward risk or a difference in exposure to smoking. Men are more likely to be in contact with smokers than are women so that they will have lower risk perceptions if these experiences provide lower perceptions of risk than the anti-smoking campaign efforts. Both the $Y O U N G$ and $M A L E$ coefficients remain strongly significant in all five specifications so that these effects are not attributable to the omission of other substantive variables.

Equation 2 of table 4 adds a series of four variables that pertain to whether the individual has heard different statements about cigarette smoking, thus capturing the role of various forms of information that has been received. In particular, respondents were asked whether they had heard that "cigarette smoking will most likely shorten a person's life" (SHORTENS LIFE dummy variable-d.v.), "cigarette smoking is dangerous to a person's health" (DANGEROUS TO HEALTH d.v.), "cigarette smoking is bad for a person's health but not dangerous" ( $B A D, N O T$ $D A N G E R O U S$ d.v.), and "cigarette smoking is not bad for a person's health" (NOT BAD FOR $H E A L T H$ d.v.). These variables represent different $X_{3}^{\prime}$ values in equation (3) above.

The four informational variables included in equation 2 of table 4 have little effect on risk perceptions, which suggests that these statements have little informational content beyond what people already know. Two of the variables have coefficients that are not statistically significant, and the other two are of small magnitude. Somewhat surprisingly, the statement that is closest to the 1965 Surgeon General's warning (DANGEROUS TO HEALTH) is associated with a risk perception 0.02 lower than average. A somewhat greater negative discrepancy is observed for $B A D$, NOT DANGEROUS.

Equation 3 in table 4 includes a dummy variable for whether the respondent has ever smoked either in the past or at present. Since this variable could potentially be endogenous, this possibility was tested formally and rejected. ${ }^{20}$ The results for equation 3 in table 4 indicate that past smoking has the expected negative effect on risk perceptions, as a history of smoking reduces the perceived RISK probability by 0.07 .
Equations 4 and 5 in table 4 report on estimates from the simultaneous equations system. The CURRENT SMOKER variable has been jointly estimated using the two stage procedure described above, and the PAST SMOKER variable is also an instrumental variables estimate. ${ }^{21}$ Both of the smoking status variables have significant negative effects on the risk assessment, as a CURRENT SMOKER will assess the lung cancer probability as being 0.08 lower and a PAST SMOKER will assess the probability as being 0.05 lower. Equation 5 adds the selectivity bias term $L A M B D A$, which is not statistically significant.

\section{Age Differences in Smoking Behavior}

The costs associated with altering one's consumption behavior are only of consequence if there is a change in one's optimal consumption decision over time. One prominent source of change is individual learning. If individuals begin smoking at a young age because they underassess the risk and then subsequently increase their risk perceptions, there may be expected welfare benefits associated with quitting. The transactions costs associated with quitting may make this a costly process of learning and adaptation, so that there will be a welfare loss as compared with the situation of full information regarding the actual risk level. It is often suggested by critics of cigarettes that individuals become lured into smoking in this manner. The results in sections III and IV did not indicate any such age-related bias. In fact, the opposite bias was evident.

The risk perception results do not in and of themselves eliminate the potential for irrational behavior by younger age groups. Other potential health hazards of smoking and one's understanding of the costs of changing one's smoking behav-

\footnotetext{
${ }^{20}$ Using the demographic variables and a set of 50 refined regional variables as instruments, one can estimate the instrumental variables for PAST SMOKER or SMOKER, which is included in addition to the variables in table 4 . This constructed variable had an estimated value of 0.0316 and a standard error of 0.0929 so that one cannot reject the hypothesis that the original PAST or CURRENT SMOKER variables are not endogenous. The smoking variable consequently passes the Hausman (1978) specification test. The excluded instrument set (i.e., the regional variables) also passes a test of overidentifying restrictions. Finally, making a distinction between past and current smokers was not consequential, as there was no statistically significant difference in the effects.

${ }^{21}$ The instrument set was the same as was used to estimate the reduced form SMOKER equation.
} 
Table 5.-Summary of Teenager-Risk Perception Interactions for Probit Estimation of Smoking Probability Equation

\begin{tabular}{lccc}
\hline \hline & \multicolumn{3}{c}{ Coefficients (std. errors) } \\
\cline { 2 - 4 } Specification & $R I S K$ & YOUNG & YOUNG $\times R I S K$ \\
\hline & & Probit Estimates \\
Basic Equation & $-0.6716^{\mathrm{a}}$ & $-0.4119^{\mathrm{a}}$ & 0.2976 \\
& $(0.0999)$ & $(0.1614)$ & $(0.2976)$ \\
Basic and Ideas Heard & $-0.6872^{\mathrm{a}}$ & $-0.4435^{\mathrm{a}}$ & 0.3246 \\
Equation & $(0.1004)$ & $(0.1623)$ & $(0.2982)$ \\
Basic and Attitudes & $-0.4992^{\mathrm{a}}$ & -0.3009 & 0.4811 \\
Equation & $(0.1391)$ & $(0.2112)$ & $(0.3869)$ \\
Basic and Ideas Heard & $-0.5192^{\mathrm{a}}$ & -0.3383 & 0.0772 \\
and Attitudes Equation & $(0.1402)$ & $(0.2134)$ & $(0.3887)$ \\
& Simultaneous Equation Probit Estimates \\
Basic Equation & $-0.9998^{\mathrm{a}}$ & $-0.3942^{\mathrm{a}}$ & 0.3032 \\
& $(0.1289)$ & $(0.1605)$ & $(0.2965)$ \\
Basic and Ideas Heard & $-1.0275^{\mathrm{a}}$ & $-0.4271^{\mathrm{a}}$ & 0.3339 \\
Equation & $(0.1300)$ & $(0.1614)$ & $(0.2973)$ \\
Basic and Attitudes & $-0.6459^{\mathrm{a}}$ & -0.2608 & 0.0185 \\
Equation & $(0.1812)$ & $(0.2090)$ & $(0.3831)$ \\
Basic and Ideas Heard & $-0.6776^{\mathrm{a}}$ & -0.2990 & 0.0131 \\
and Attitudes Equation & $(0.1833)$ & $(0.2113)$ & $(0.3852)$ \\
\hline a Coefficients are statistically significant at the 5\% level, one-tailed test. &
\end{tabular}

${ }^{a}$ Coefficients are statistically significant at the $5 \%$ level, one-tailed test.

ior also enter. Moreover, one must also show that this group acts upon these perceptions in making their smoking decisions.

To analyze smoking behavior, let the dependent variable be whether or not the individual smokes, which is a dichotomous $0-1$ variable. The subsequent analysis of smoking behavior will consider the effect on smoking of a series of risk perception and personal characteristic variables. The first four equations in table 5 report the probit estimates of the smoking equation, where $R I S K$ is not treated as endogenous. The second set of equations at the bottom of table 5 report the probit estimates obtained using the simultaneous model discussed in section IV.

Four different probit specifications are addressed in table 5. All equations include the lung cancer risk perception (RISK), whether the respondent is in the YOUNG age cohort, and an interaction between YOUNG and RISK to identify a possible difference in smoking behavior. The basic equation includes these measures as well as three demographic variables and seven regional dummy variables. The second equation adds a series of four dummy variables for various ideas that the individual may have heard about smoking, such as that smoking is dangerous to one's health. These variables capture in part omitted aspects of risk information that may be pertinent to smoking behavior. The third specification adds a series of 24 smoking attitude $0-1$ dummy variables. These variables are the results of an open-ended memory recall task in which the surveyor elicited the respondent's attitude toward smoking behavior. ${ }^{22}$ The overwhelming majority of the attitude probe responses were negative, as respondents indicated that smoking causes cancer, affects health, shortens life, or is otherwise unattractive. These memory recall variables capture tastes and omitted aspects of risk perceptions not reflected in the lung cancer variable.

The results are similar in each case. For each of the four specifications there is no statistically significant difference in the smoking behavior of the youngest age cohort in the sample. The greater risk assessments of the YOUNG group are transmitted into reductions in smoking behavior in the same manner as for the rest of the population. In particular, the independent effect of the YOUNG coefficient and the interactive effect of YOUNG with RISK are consistently not statistically significant. Moreover, the independent influence of RISK indicates a significant

\footnotetext{
${ }^{22}$ This technique is utilized in Magat, Viscusi, and Huber (1988), and as is indicated in that paper this memory recall task will not bias subsequent risk perception questions in the survey.
} 
negative effect of lung cancer risk perceptions orsmoking behavior. These effects appear to be somewhat greater for the simultaneous equation model.

\section{Conclusion}

The patterns of smoking and risk perceptions accord with one's expectations given the character of the risk information that has been provided. There has been a tremendous amount of publicity devoted to the hazards of smoking. Given the pronounced tendency to overestimate prominent risks, one would expect individuals to overestimate smoking risks. This bias does not reflect a failure to process risk information accurately, as the typical form of governmental risk information transfer indicates that a hazard is present but does not indicate its specific probability.

The observed pattern of risk perceptions accords with what one would expect given the different mix of risk perceptions for different segments of the population. Most important is that the youngest age cohort has a high risk perception and is more likely to overestimate the risk than the population at large, which reflects their substantial reliance on recently provided information pertaining to smoking risks.

The presence of substantial perceptions does not necessarily imply that the subsequent smoking decisions by younger individuals will be rational. The empirical evidence does indicate that perception of the risks influences smoking behavior. Moreover, examination of the determinants of smoking behavior indicates that there is no statistically significant difference in the manner in which risk perceptions influence smoking behavior for the youngest age cohort. These results are also pertinent to formulation of economic models of smoking "addiction" since any welfare losses associated with costs of changing consumption behavior depend on the rationality of one's decisions at the time when this consumption is initiated. $^{23}$

\section{REFERENCES}

Akerlof, George, and William Dickens, "The Economic Consequences of Cognitive Dissonance," American Economic Review 72 (1982), 307-319.

\footnotetext{
${ }^{23}$ The rationality of decisions is a fundamental ingredient of rational addiction models, such as Becker and Murphy (1988).
}

Arnould, Richard, and Henry Grabowski, "Auto Safety Regulation: An Analysis of Market Failure," Bell Journal of Economics 12 (1981), 27-48.

Becker, Gary, and Kevin Murphy, "A Theory of Rational Addiction," Journal of Political Economy 96 (1988), 675-700.

Blomquist, Glenn, The Regulation of Motor Vehicle Traffic Safety (Boston: Kluwer Academic Publishers, 1988).

Camerer, Colin, and Howard Kunreuther, "Decision Processes for Low Probability Risks: Policy Implications," Journal of Policy Analysis and Management 8 (4) (1989), 565-592.

Combs, B., and P. Slovic, "Causes of Death: Biased Newspaper Coverage and Biased Judgments," Journalism Quarterly 56 (1979), 837-843.

Cook, Philip, and George Tauchen, "The Effect of Minimum Drinking Age Legislation on Youthful Auto Fatalities, 1970-1977," Journal of Legal Studies 13 (1984), 169-190.

Fischhoff, Baruch, et al., Acceptable Risk (Cambridge: Cambridge University Press, 1981).

Hamilton, James, "The Demand for Cigarettes: Advertising, the Health Scare, and the Cigarette Advertising Ban," this REVIEW 54 (1972), 401-411.

Hausman, Jerry A., "Specification Tests in Econometrics," Econometrica 46 (1978), 1251-1271.

Heckman, James, "The Common Structure of Statistical Models of Truncation, Sample Selection, and Limited Dependent Variables and a Simple Estimator for Such Models," Annals of Economic and Social Measurement 5/4 (1976), 475-492.

Kmenta, Jan, Elements of Econometrics, second edition (New York: Macmillan, 1986).

Kunreuther, Howard, et al., Disaster Insurance Protection (New. York: Wiley, 1978).

Lichtenstein, Sara, et al., "Judged' Frequency of Lethal Events," Journal of Experimental Psychology: Human Learning and Memory 4 (1978), 551-578.

Maddala, G. S., Limited-Dependent and Qualitative Variables in Econometrics (Cambridge: Cambridge University Press, 1983).

Magat, Wesley, W. Kip Viscusi, and Joel Huber, "Consumer Processing of Hazard Warning Information," Journal of Risk and Uncertainty 1 (2) (1988), 201-232.

National Safety Council, Accident Facts (Washington, D.C.: U.S. Government Printing Office, 1988).

Overholt, Richard H., Willford Neptune, and Mian Ashraf, "Primary Cancer of the Lung," Annals of Thoracic Surgery 20 (1975), 511-519.

Ringold, Debra J., and John E. Calfee, "The Informational Content of Cigarette Advertising: 1926-1986," Journal of Public Policy and Marketing 8 (1989), 1-23.

Schneider, Lynne, Benjamin Klein, and Kevin Murphy, "Governmental Regulation of Cigarette Health Information," Journal of Law and Economics 24 (3) (1981), 575-612.

Smith, V. Kerry, William H. Desvousges, Ann Fisher, and F. Reed Johnson, "Learning about Radon's Risk," Journal of Risk and Uncertainty 1 (2) (1988), 233-258.

$\rightarrow$ Smith, V. Kerry, and F. Reed Johnson, "How Do Risk Perceptions Respond to Information? The Case of Radon," this REVIEw 70 (Feb. 1988), 1-8.

U.S. Dept. of Commerce, Bureau of the Census, Statistical Abstract of the United States: 1986 (Washington, D.C.: U.S. Government Printing Office, 1985).

U.S. Dept. of Health and Human Services, The Health Conse- 
quences of Smoking: A Report of the Surgeon General (Washington, D.C.: U.S. Government Printing Office, various years).

, The Health Consequences of Smoking: Nicotine Addiction: A Report of the Surgeon General (Washington, D.C.: U.S. Government Printing Office, 1988).

Viscusi, W. Kip, Employment Hazards: An Investigation of Market Performance (Cambridge: Harvard University Press, 1979).

"A Bayesian Perspective on Biases in Risk Perception," Economic Letters 17 (1985), 59-62.

, "Predicting the Effects of Food Cancer Warnings on Consumers," Food Drug Cosmetic Law Journal 42 (1988), 283-307.

"Do Smokers Underestimate Risks?" Journal of Political Economy 98 (1990), 1253-1269.
Smoking: Making the Choice under Uncertainty (New York: Oxford University Press, 1992), in press.

Viscusi, W. Kip, and Wesley A. Magat, Learning about Risk: Consumer and Worker Responses to Hazard Information (Cambridge: Harvard University Press, 1987).

Viscusi, W. Kip, Wesley A. Magat, and Joel Huber, "An Investigation of the Rationality of Consumer Valuations of Multiple Health Risks," Rand Journal of Economics 18 (4) (1987), 465-479.

Viscusi, W. Kip, and Charles O'Connor, “Adaptive Responses to Chemical Labeling: Are Workers Bayesian Decision Makers?" American Economic Review 74 (1984), 942-956.

Wald, A., "The Fitting of Straight Lines if Both Variables Are Subject to Errors," Annals of Mathematical Statistics 11 (1940), 284-300. 